\title{
INTELLECTUAL PROPERTY AND SOFTWARE PATENTS - PRACTICAL EXPERIENCE
}

\author{
Jordán M.*
}

\begin{abstract}
Aim of this presentation is to provide guidance, how to use intellectual property (IP) tools to support research and development in the industry. It will discuss all basic IP rights such as patents, utility models, designs and trademarks. Further it will stress role of often undervalued patent searches for Inspiration, Freedom to operate and Patentability. Last but not least also software patents are presented, so it is understood, what can be patented and what cannot.
\end{abstract}

Keywords: Patent, Utility model, Design, Trademark, Software patents.

\section{Introduction}

Following chart illustrates best practice of using intellectual property (IP) and patents within a commercial company. As these tools are intended to be used for commercial success, it is advantageous to use them also when commercial application is planned or possible within research organization or university. Furthermore, even if applied research is not the case, patent search can be used to gather all information relevant to certain technology or industry. Patents include detailed technical information that is freely available to all.

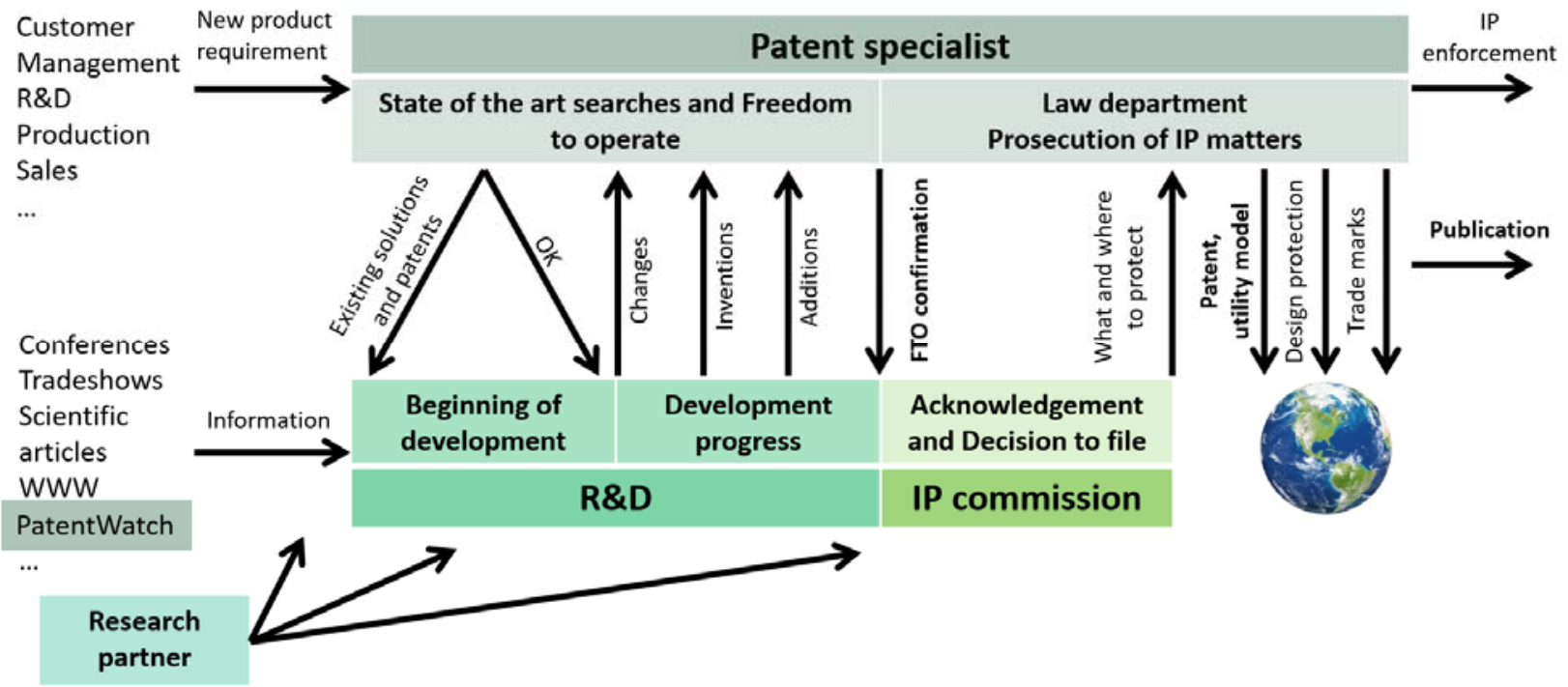

Fig. 1: R\&D process and Patent specialist.

At the beginning of the research and development process, the role of the Intellectual property (IP) field lies mainly in inspiring and providing knowledge to the researches who, thanks to the most up-to-date information, are at the peak of current knowledge in the field and thus they do not repeat research and development of others. 


\section{State of the Art Patent Search}

State of the Art Patent Searches are carried out for a specific development project and they are therefore searches aimed at finding the same or similar technical solution, which is the subject of a new research or development project assignment, i.e. before the beginning of the work on the concept. The search is for a specific technical unit or problem to be solved, without any time or territorial limitation.

Patent databases available (non-commercial available to all):

https://worldwide.espacenet.com/

https://patents.google.com/

https://app.patentinspiration.com/

http://www.freepatentsonline.com/

\section{Patent Clearance Search}

Patent Clearance Search will partially overlap with State of the Art Patent Search, but it will include a maximum of patents and applications that may have the same combination of features in any of the independent claims as the product being developed. This time, however, the search is limited to alive patents and applications, and to the territories in which the product is to be used.

Ideally, Patent Clearance Search is always performed before a major investment in research and development when it is still relatively cheap and easy to change the product, as illustrated in the graph below. Research partner is usually in position of helping the commercial partner to mitigate such risks and to understand this complex topic which is often highly appreciated.

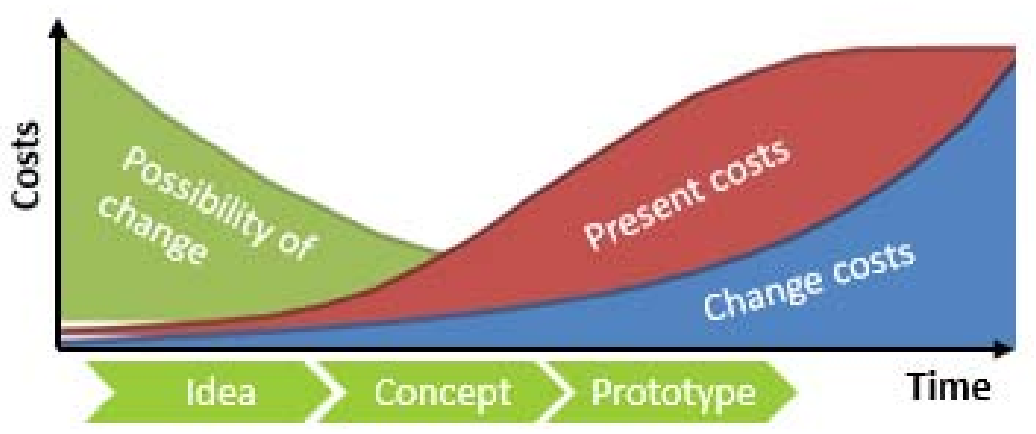

Fig. 2: Development and costs of changes.

However, at the early stage of project, it is not recommended to devote too much time to patent clearance and the scope of protection of individual patents found, because it can lead to frustration of researchers and to premature closure of development paths with the potential to create valuable solutions.

The first searches in the given technical field always show how much effort and how much time will be needed. Given the fact that we are looking for the most effective way to reduce the likelihood of conflict with the rights of others, it may be decided to further restrict the search, for example to selected companies, depending on the potential risks of infringement, the competitor's IP activity or on what is the possibility of detecting infringements. One needs to be aware that, because of many reasons, there is a risk that any type of patent searches is not complete and does not contain all relevant documents.

Patent Clearance Search requires close cooperation between the research and development staff and a patent professional and needs to be refined and adjusted as the R\&D changes and updates the technical solution. The whole product and all its technical units are examined regardless of whether any part is or is not the subject of a patent of the company. 


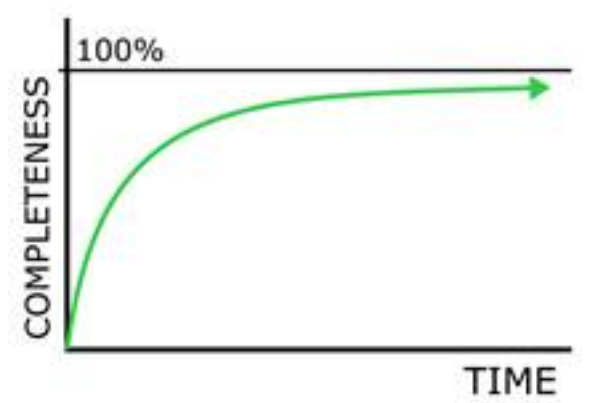

Fig. 3: Illustration of the search progress with regard to its completeness.

There is no need to perform Patent Clearance Search when:

a) solution has been known (published) for more than 20 years,

b) the entire solution is described in an expired patent,

c) on the basis of a contractual agreement, the company is relieved of liability for patent clearance (FTO - Freedom To Operate),

d) the solution can be kept entirely secret to potential right holders,

In all other cases, it is recommended to perform the search, wherein the importance of the Patent Clearance Search increases in particular with the size of the risk of business losses and reputational damage, the potential conflict with competitors in a given market, and the aggressiveness of competitors. Given the potentially enormous complexity, it may also be reasonable to "intuitively" select the riskiest technical units and review them.

Another aspect to consider is the potential costs of resolving a dispute, possibility of settlement of potential conflict, and the ability to replace the conflicting solution with a solution not infringing any patent rights. The costs of a potential dispute include court costs and attorney fees, which vary from territory to territory and typically amount to more than hundreds of thousands of euros for a single patent dispute abroad.

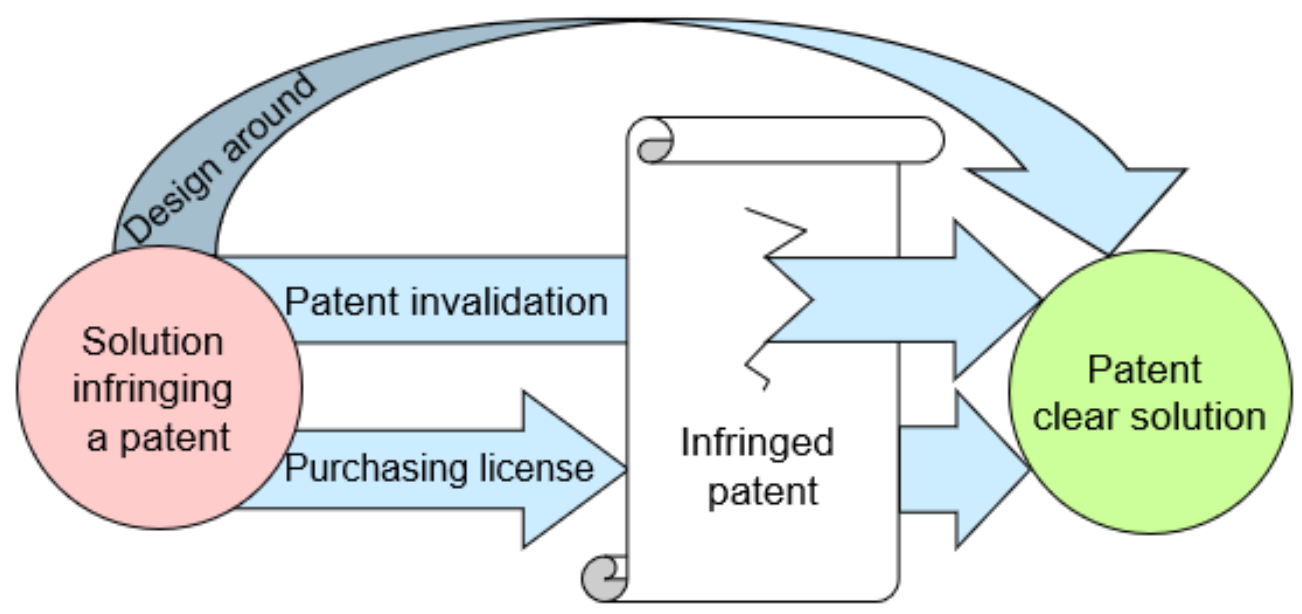

Fig. 4: Methods of solving patent collision.

Therefore, it is important to handle any discovered collision. Such collision can be solved in the following ways; the individual options shall be reviewed in chronological order according to the following list:

a) Design around main patent claims.

b) Invalidate patent or prevent grant thereof - actively or prepare arguments for its revocation (or necessary narrowing of the scope of protection) for later use in the event of opposition by competitor.

c) Examine the possibility of purchasing the necessary license. 


\section{Patentability Search}

Once the research and development phase of project is completed and it is clear what the technology or product will look like, it is important to examine, before its publication, whether it is convenient to seek patent or design protection of any of the technical features, as it is illustrated in Fig. 1. If needed, a State of the Art Patent Search is additionally done and patentability of the selected units is evaluated.

\section{Conclusions}

Having presented major searches related to research and development it is clear that there is much more than just patent filings to consider on projects. Usually patent filing is considered only after completion of all relevant patent searches. What can be patented including software applications is further discussed in presentation enclosed. 